\title{
Limits to Cycles and Harmony in Revolutions
}

\author{
THEODORE MODIS
}

ABSTRACT

The work presented here discusses difficulties and rewards associated with research and publication on the topic of cycles. Experiences and highlights are mainly drawn from two books by the author: Predictions, Simon and Schuster, 1992, and Conquering Uncertainty, McGrawHill, New York, 1998. Much of the content of these books has appeared over the years in various articles published in this journal.

* Theodore Modis is the founder of Growth Dynamics, an organization specializing in strategic forecasting and management consulting.

Address reprint requests to: Rue Beau Site 2, 1203 Geneva, Switzerland

E-mail:tmodis@compuserve.com 


\section{Cycles: A Love-Hate Involvement}

My first book Predictions was groomed to be a best seller. Simon \& Schuster was perplexed when it did not become one. Among the possible explanations may be in part the fact that an early prestigious book review, Kirkus Reviews, concluded with the following caustic remarks: "Capping all this predictive optimism about optimization and natural evolution are ... are you ready for it? Cycles."

Academic people, from researchers in departments of economics all the way to physicists in particle accelerators, are in general unfriendly disposed toward cycles. They tend to think of the subject as akin to non-sciences such as numerology and astrology. The harder the science where they come from, the greater is their rejection. One of the several Herculean tasks set for me as a pre-condition by Simon \& Schuster (before they agreed to a handsome advance for the book) was advance praise, i.e., endorsements by world renowned scholars such as Nobel Prize winners. I naturally turned toward the handful Nobel Prize winners I knew as a physicist. The first one I approached was my teacher, Jack Steinberger, Nobel Prize 1988. He had been my Ph.D. research adviser at Columbia University. When I showed him an early version of the manuscript with a tentative title Forecasting Destiny, he brushed it aside with the remark: "You know me Ted, I don't read this kind of stuff."

Simon van der Meer, Nobel Prize in physics 1986, was more friendly. He read the manuscript, found it interesting, well-written, enjoyable, controversial, and thought-provoking. But there was a snag with him too. He would not authorize his signature to appear on any document that carried the word astrology, and at that time the book had a section heading "How to Defend Astrology without Risking Your Reputation". The section put forth an explanation for the 56-year Kondratieff cycle as due to a climatic variation, which itself can be linked to periodicity in the various sun-moon-earth configurations. Van der Meer agreed with my thesis, but would not give his endorsement until I assured him that the word astrology would be barred from the entire book. But in contrast to Steinberger, he was intrigued by the idea of the existence of a cycle. In fact, he volunteered an explanation of his own drawing from his expertise in stochastic phenomena. His explanation resonates with the central theme of the article by Mallmann and Lemarchand in this issue. According to van der Meer, an individual can actively influence the environment for a period of about fifty years. Individuals consequently act as fixed "delays" in a never-ending flux of change. In society there are many feedback loops, and despite a continuous arrival of individuals, the existence of a fixed delay-triggered by an instabilitycould produce "bunching" phenomena with a characteristic period equal to the delay.

The fascination around cycles stems from the fact that they offer predictability, particularly for what concerns a change in the direction. As if one could see around corners. At the same time, it is this very fascination that contributes to the cycles' detriment, because predictability entails predeterminism and thus infringes upon free will. Things would still be manageable - emotionally - if the predictability concerned linear or at least monotonic growth. Passionate reactions are not really provoked by predictions of world-population growth, or by stock-market growth. But to say that there will be regular and inevitable downs, e.g., the stockmarket crashing every fifty-six years, or that war activities will flare up every twenty-five years, is sure to trigger emotional response, anxiety, and possibly anger. People do not like the idea that they are not getting better, and they do not want to be told that they do not have any choice. So they react emotionally attacking the very existence of cycles.

The most virulent and most effective attacks on cycles come from scientifically-minded people who know about the origin of and how to treat uncertainties in observation. Kondratieff himself has been rather discredited for many decades (and still is today in some departments around the world). It was in the 1920s and without the help of computers or calculating 
machines that Kondratieff deduced an economic cycle with a period of about fifty years from monetary indicators alone. However, critics doubted both the existence of Kondratieff's cycle and the causal explanation suggested by Schumpeter. The postulation ended up being largely ignored by contemporary economists. The most significant reason for this rejection may have been the boldness of the conclusions drawn from such ambiguous and imprecise data as monetary and financial indicators. These indicators, like price tags, are a rather frivolous means of assigning lasting value. Inflation and currency fluctuations due to speculation or politicoeconomic circumstances can have a large unpredictable effect on monetary indicators. Extreme swings have been observed. For example, Van Gogh died poor, although each of his paintings is worth a fortune today. The number of art works he produced has not changed since his death; counted in dollars, however, it has increased tremendously.

But the best defense of cycles is also to be found in the scientific method. In observing cycles with a period of fifty-six years I have cited numerous examples in Predictions, all of which are based on physical quantities. ${ }^{1}$ Energy consumption, the use of transportation, the discovery of stable elements, the succession of primary energy sources, criminality, the spreading of diseases, and creative achievement have all been reported in their appropriate units and not in relation to their prices. Moreover, to insure defensible results, whenever the data set could be subject to subjective judgment (e.g., "basic" innovations, and "valid" Mozart composition), independent confirmation of the data quality by third parties was sought. The cycles obtained this way then become trustworthy. I felt vindicated when a review of my book in Science in February 1993 acknowledged this fact:

“... he (Modis) does cite the relationship of his 'overall' 56-year cycles and evidence on the associated clustering of technological innovations to prior work by Kondratieff and Schumpeter (in my opinion, Modis' evidence on these topics is more extensive and compelling than that of either of these scholars.)"

\section{A Proliferation of Cycles}

In the wake of New Age the topic of cycles has surfaced again gaining attention and respectability. Some of the new supporters are hard-core scientists. Jay Forrester at MIT was able to reproduce Kondratieff's long wave with his sophisticated System Dynamics model, via major shifts in private-sector incentives for investing in capital plant, borrowing, and savings. ${ }^{2}$ Cesare Marchetti at IIASA, analyzed quantitatively many cyclical patterns in human affairs. ${ }^{3}$ Finally, a new book by Kondratieff himself surfaced. This is a monumental work (550 pages) published by his followers in a respectable French publishing house. ${ }^{4}$

It is tempting to jump on the cycle wagon and begin looking for and even "seeing" cycles just about everywhere. Upon the fourth observation corroborating fundamental changes in my life eleven years apart, I was ready to deduce an 11-year cycle for my person. Marchetti was quick to point out that this is the period of the variation in the sunspots activity, and it turns out that the sun does rule my astrological sign! But all this is tantamount to opening a Pandora's box. How fundamental is a change? To get divorced eleven years after getting married is one thing, but does it also count if one only changes jobs, or just houses? How likely am I to pick and call a "fundamental change" an event that simply falls close to the period of the cycle I am studying? Some years ago, an excited young colleague drew me into scanning world history atlases for significant events 56-years apart. I was quick to abandon that search and it is not for lack of data. On the contrary, practically any conclusion would have been possible to demonstrate! 
The article of Mallmann and Lemarchand in this issue features an extensive list of cycles, and an even more extensive list of references and publications on the subject, and yet, one could add to both. They say nothing, for example,-and this is to their credit-about the plethora of cycles proliferating in connection to the stock market. But they should have mentioned the existence of the Foundation for the Study of Cycles. ${ }^{5}$ This institution, founded in 1941, publishes and/or gives reference to an incredible amount of literature on cycles. The fundamental difficulty with this extensive spectrum of cycles is always the same: how to establish objectively chosen, quantitative and reliable sets of data. This difficulty translates to what can be establish. A great physicist once told me that experiments are either trivial or impossible. What he meant was that scientific rigor can make abstraction of technical difficulties but must respect the laws. In that perspective, to evidence a cycle for female fertility is trivial. The work has been done on data found in the Statistical Abstracts of the US. ${ }^{6}$ The cycle spans about forty years with a mid point at the age of twenty-four. But despite increasing popularity on the subject, to establish a cycle for male menopause is impossible.

The proliferation of cycles has another negative aspect. Inflationary tactics lead to devaluation. The Foundation for the Study of Cycles exerts little attraction on me. I refused an invitation by one of New York's twelve largest publishing firms to write an "exhaustive" book on cycles. I felt that Kondratieff's cycle has taken the cream off this subject, and that indulging in a variety of other less evident cycles would subtract rather than add to the credibility of the topic. Of course there are indisputable shorter cycles. The four seasons, the day-night cycle, the weekly cycle, women's menstrual cycle, or the short cycle of respiration. They all influence our lives. There are also less obvious cycles, and to stay with cycles not covered in the paper of Mallmann and Lemarchand I mention here: the cycle of Saros (18 years), known since antiquity, the cycle of Meton (19 years), used in the calculation of the date of Easter, and the cycle of Gleissberg (80-90 years), connected to the secular sunspot cycle, according to which, and contrary to popular belief, we are heading toward a little ice age rather than global warming. ${ }^{7}$

Wanting to take some distance from the topic of cycles per se does not only stem from wishing to safeguard self respect. I have been becoming increasingly aware that the understanding from cycles adds value continuously. The final punch line may be more spectacular than useful. Predicting Mozart's time of death is lesser a piece of information than predicting what he would/could do while alive. Having presented ample evidence in Predictions that the length of one's productivity/creativity cycle correlates to one's life span - inspired by the work of Cesare Marchetti ${ }^{8}$ - I treat in Conquering Uncertainty the possibility of enjoying a second cycle in a life time, and even a third one. ${ }^{9}$ There are rules to observe and advice one can use, if one wants to maximize his or her chances for a "Second Lease on Life."* Cycles tell more than just what will happen at a certain time in the future. They reveal how one gets there.

\section{Harmony in Revolution}

Cycles can be seen as natural phenomena because they are intimately linked to natural growth. When we look at the rate of growth, a chain of growth steps produces a stream of bell-shaped curves, which is nothing else but a long wave. Figure 1 shows a harmonic cascade of growth steps and the wave it gives rise to. It is called harmonic here because the timing of the

\footnotetext{
* This is the name of a software system, based on ideas from Conquering Uncertainty, appropriate among other things for the just-in-time launching of new products.
} 
succession - overlap between stages - is such that the overall envelope becomes a sine wave, the signature characteristic of harmonic motion, the motion of the pendulum.

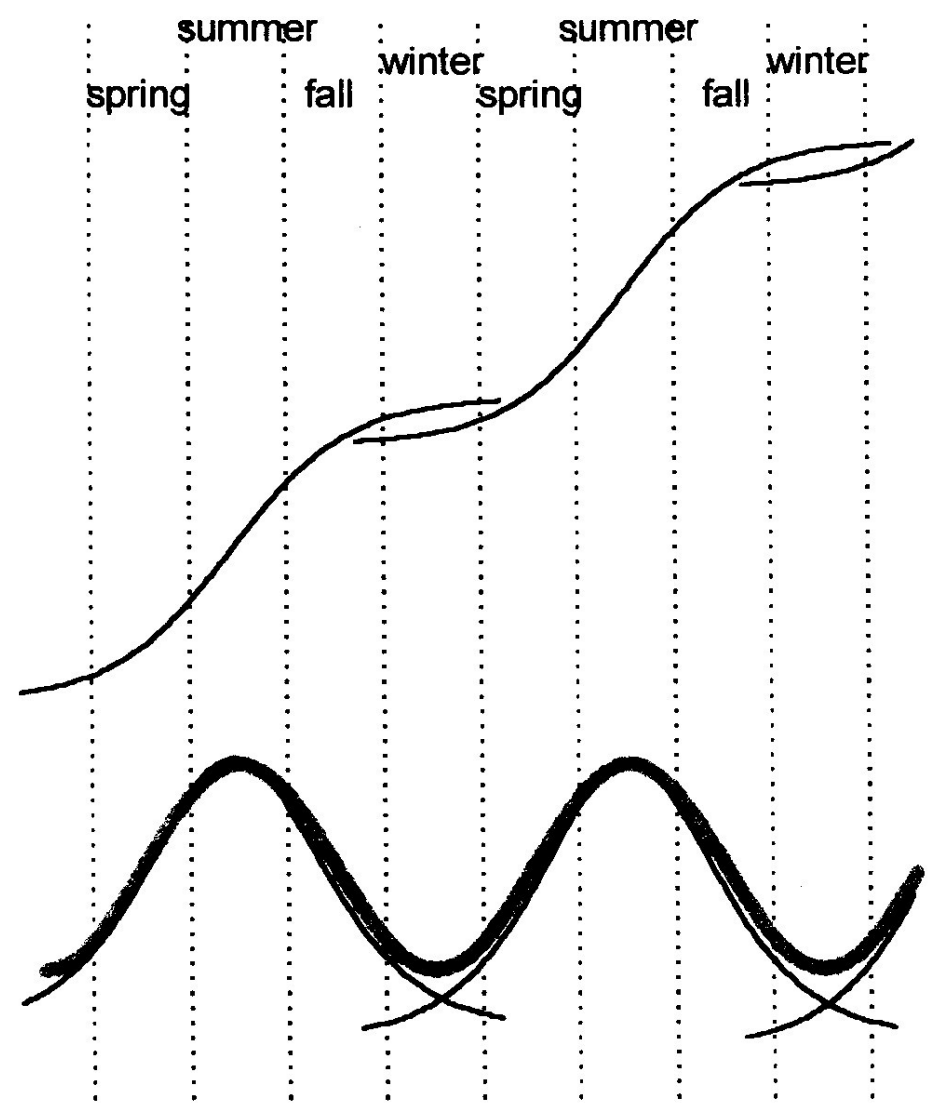

Figure 1. We see a harmonic cascade of three natural-growth steps (size at the top, rate of growth at the bottom). The thick gray line is a sinusoidal wave and it coincides with the sum of the bell-shaped curves it envelopes. Seasons are assigned to the different growth phases.

We also see in Figure 1 four stages that in principle can be associated with every naturalgrowth cycle. These stages carry the name and play the role of the four seasons. Summer is the high-growth period around the mid-point of the growth process. Winters are the low-growth periods one finds at the end and at the beginning of each process. Spring is the period between winter and summer characterized by a progressively rising growth rate. Fall is the time between summer and winter, when the rate of growth continuously declines. This metaphor serves more than just as a mnemonic device or a poetic image. It can be a key to decision making. Our familiarity with mechanisms and behaviors associated with nature's four seasons can shed light and guide us through decision about business issues and other social endeavors. For example, the low creativity observed during a summer is only partially due to the heat in the weather. New undertakings are mainly disfavored because the living is easy and there is no reason to look for change. In contrast, animals (for example, foxes and sparrows) are known to become entrepreneurial in the winter. There is wisdom encoded in nature's seasonal patterns and behaviors. One can study and transfer them to whatever situation depicts a succession of seasonlike stages.

The repercussions of such a classification are far-reaching. For example, the concept of just-in-time manufacturing, with its popularized success in the beginning of the 1990s, corresponds to only one of many entries in this classification scheme. It was mentioned earlier 
that summers tend to be periods of conservatism and winters periods of innovation. But other sacred notions, such as excellence and enterpreneurship are also seasonal. The amount of limelight they receive-i.e., their relative importance-depends on the season. TQM (total quality management), as exemplified in the zero-defect motto, fits better in a summer. BPR (business process re-engineering) is typically a winter endeavor. Benchmarking (comparing yourself to the best in class) is more appropriate in the fall, when you find out that something is no longer going quite right. Learning and investing is more appropriate in spring. Sowing for the future crop - e.g., launching the replacement product — is best done during the fall of the present one. Fundamental change and revolution come naturally in the winter, but vertical integration and unification in the summer.

The seasons metaphor enables a timeliness of action that gives intellectual and material satisfaction. Charles Handy, the management consultant guru, has advocated uninterrupted vigilance for the turning point. The beginning of the downturn, he warns, is to be assumed imminent at all times, because "there is no science for this sort of thing". But the idea of stubbornly and continuously preparing for disaster comes as an insult to the intelligent human species. It is as inefficient to continuously gear for disaster as it is dangerous to assume that the good days will last forever. Understanding the phases of a cycle can help anticipate the next turning point with sufficient accuracy for just-in-time action.

Harmony is associated with the patterns and behaviors observed during the different seasons. One can easily interpret any social or biological wave as a chain of bell-shaped curves arising from harmonically cascaded growth steps governed by Darwinian competition-survival of the fittest. The seasonal behavioral patterns observed in nature have undergone natural selection and consequently they are the ones best-fit to survive. In a way, what we see is the best that could have happened, and consequently what should happen. Is your "baby" (project, company, entrepreneurial activity, or relationship) appropriately dressed for the season it is traversing?

\section{What to Do}

Besides those excited about cycles because they will find out when the next boom or bust will be, there are those who reject cycles because they believe the future lies squarely in their hand, and also those who simply do not want to know what will happen. But there is no infringement on one's free will. The predeterminism ingrained in cycles only works at the aggregate level; individuals will always be free to go against the current. There is no magic either. Death comes naturally in winter, but it does not have to be this winter. Understanding, tuning in, and exploiting the opportunities of the season one is traversing can be instrumental in ensuring another set of seasons. Mozart did not have to die at thirty-five; not everyone died from an epidemic at that time. There is evidence that his musical creation was approaching saturation. ${ }^{*}$ But he could have spawned a second cycle of creativity, just as Hittchcock did when his film career entered a season of fall and he embarked on the celebrated television series Alfred Hitchcock Presents. Cascading careers are known to exist and play a decisive role in long happy lives. Football players do not necessarily die upon retirement from the playing ground. Many retirees embark on new activities with success.

In fact, Mozart did make a feeble attempt to branch out - at least one may interpret it that way. He composed the Dissonant Quartet in C Major, K465 in 1985 appropriately during the fall season of his career. But the music lovers of his time could not accommodate the kind of

\footnotetext{
${ }^{*}$ First suggested by Marchetti [8] and later re-examined by Modis [1].
} 
music that became acceptable one hundred and fifty years later (e.g., Bartok). Mozart was forced to stop exploring musical directions that provoked public rejection.

To turn to cycles in order to hit the jackpot may be as unrealistic as unappetizing. Good forecasts can run into bad luck. "Exceptions" happen even in the precise astronomical world. I have evidenced the absence of one period out of five witnessed in a long wave modulating sunspot activity. ${ }^{10}$

There is, however, a more rewarding goal to set while studying cycles: put to work the detail understanding of the evolutionary process and secure for yourself one more round of seasons.

\section{REFERENCES}

\footnotetext{
${ }^{1}$ Modis, T.: Predictions. Simon \& Schuster, New York, 1992.

${ }^{2}$ Forrester, J.: System Dynamics and the Lessons of 35 Years, a chapter for The Systemic Basis of Policy Making in the 1990s, edited by Kenyon B. De Greene, 1991.

${ }^{3}$ Marchetti, C.: Fifty-Year Pulsation in Human Affairs, Analysis of Some Physical Indicators, Futures, vol. 17, no. 3, pp. 376-88 (1986).

${ }^{4}$ Kondratieff, N.: Les Grands Cycles de la Conjoncture. Economica, Paris, 1992.

${ }^{5}$ Foundation of the Study of Cycles, 900 W. Valley Rd., Suite 502, Wayne, PA 19087

${ }^{6}$ See Predictions above.

${ }^{7}$ Landscheidt, T.: Global Warming or Little Ice Age, Journal of Coastal Research, Special Issue No. 17:

Holocene Cycles: Climate, Sea Levels, and Sedimentation, pp. 371-382

${ }^{8}$ Marchetti, C.: Action Curves and Clockwork Geniuses, International Institute of Advanced System Analysis, Laxenburg, Austria, April 1985.

${ }^{9}$ Modis, T.: Conquering Uncertainty. McGraw-Hill, New York, 1998.

${ }^{10}$ See Predictions above.
} 